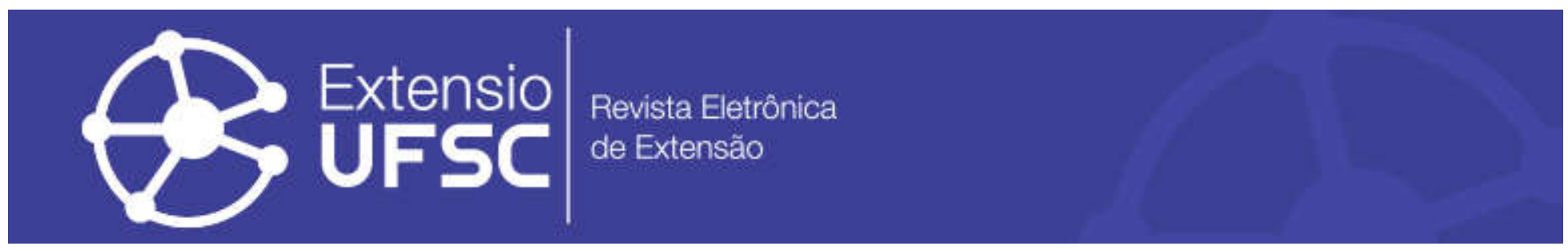

\title{
CARACTERIZAÇÃO DA PISCICULTURA FAMILIAR NA REGIÃO DO BAIXO PARNAÍBA - ARAIOSES/MA
}

\author{
Jane Mello Lopes \\ Universidade Federal do Maranhão \\ janemellolopes@hotmail.com \\ Maecio Dennis Costa dos Santos \\ Universidade Federal do Maranhão \\ maeciodennis@hotmail.com \\ Antonia Mara Nascimento Gomes \\ Universidade Federal do Maranhão \\ nascimento.antonia@ufma.br
}

\author{
Francisca Erica do Nascimento Pinto \\ Universidade Federal do Maranhão \\ ericanascimentop@hotmail.com
}

André Wallas da Silva Sousa Instituto Federal de Educação do Maranhão andre.wallas@ifma.edu.br

Nataline Carneiro Marques

Universidade Federal do Maranhão nataline1601@hotmail.com

\section{Resumo}

Este estudo objetivou caracterizar as pisciculturas no município de Araioses/MA, visando subsidiar estratégias para o desenvolvimento da atividade na região. Foram realizadas entrevistas semiestruturadas, para o levantamento de dados socioeconômicos, de produção e comercialização, além da realização de palestras de capacitação. Entre os entrevistados, $81 \%$ se declararam do gênero masculino e $63 \%$ utilizam mão de obra familiar. Nas criações prevalecem os viveiros escavados onde as principais espécies criadas são a tambatinga (44\%) e a tilápia (35\%) alimentadas com ração comercial duas vezes ao dia $(56 \%)$. A comercialização ocorre na própria comunidade quando os peixes atingem entre $250-400$ g. Os parâmetros de qualidade de água na criação apresentaram-se adequados, com exceção da salinidade. É dominante o trabalho individual e informal, com limitações em relação à gestão, planejamento e manejo geral da atividade. A partir das ações de capacitações (palestras e orientações in loco), acredita-se ter contribuído em relação ao manejo que os criadores vinham realizando. Apresentam deficiência de recursos, de infraestrutura e assistência técnica. Estes últimos fatores permitem compreender o porquê do abandono da atividade por parte significativa de piscicultores. No entanto, apesar dos problemas técnicos e de gestão identificados, a piscicultura mostrou importância na diversificação da renda e segurança alimentar da família dos piscicultores assistidos.

Palavras-chave: Agricultura Familiar. Produção de Peixes. Qualidade da Água.

\section{CHARACTERIZATION OF FAMILY FISH FARMING IN LOWER PARNAÍBA REGION - ARAIOSES/MA}

\begin{abstract}
This study aimed to characterize fish farming in Araioses / MA, in order to subsidize strategies for the development of activity in the region. Semi-structured interviews were carried out to survey socioeconomic, production and marketing data, as well as training lectures. Among the interviewees, $81 \%$ declared themselves to be male and $63 \%$ use family labor. In the creations the excavated nurseries prevail where the main species created are tambatinga (44\%) and tilapia $(35 \%)$ fed with commercial feed twice a day (56\%). Marketing takes place in the community itself when the fish reach $250-400 \mathrm{~g}$. The parameters of water quality in breeding were adequate, with the exception of salinity. Individual and informal work is dominant, with limitations in relation to the management, planning and general management of the activity. Based on the training actions (lectures and on-site guidance), it is believed to have contributed in relation to the management that the breeders had been carrying out. They lack resources, infrastructure and technical assistance. These last factors make it possible to understand the reason for the abandonment of the activity by a significant part of fish farmers. However, despite the technical and management problems identified, fish farming has shown importance in diversifying the income and food security of the family of assisted fish farmers.
\end{abstract}

Keywords: Family Farming. Fish Production. Water Quality. 


\title{
CARACTERIZACIÓN DE LA PISCICULTURA FAMILIAR EN LA REGIÓN DEL BAJO PARNAIÍBA - ARAOSES/MA
}

\begin{abstract}
Resumen
Este estudio tuvo como objetivo caracterizar las granjas piscícolas en Araioses/MA, con el fin de apoyar estrategias para el desarrollo de esa actividad en la región. Se realizaron entrevistas semiestructuradas, para recolectar datos socioeconómicos, de producción y de comercialización, adicionalmente se realizaron talleres de capacitación. Entre los encuestados, el 81\% pertenece al género masculino, y el 63\% utiliza mano de obra familiar. En la producción prevalecen los estanques excavados, las principales especies criadas son la tambatinga (44\%) y la tilapia (35\%) alimentadas principalmente con ración comercial administrada dos veces al día $(56 \%)$. La comercialización ocurre en la propia comunidad cuando los peces alcanzan entre 250 y $400 \mathrm{~g}$. Los parámetros de calidad de agua en los criaderos de forma general son adecuados, a excepción de la salinidad durante el periodo seco en la región. El trabajo individual e informal es dominante, con limitaciones en relación a la gestión, planeación y manejo general de la actividad. Baseado em las acciones de capacitación (conferencias y orientación en el sítio), se cree que ha contribuição em relación con la gestión que los criadores habían llevado a cabo. Se presenta deficiencia de recursos, infraestructura y asistencia técnica. Estos últimos factores permiten comprender la razón del abandono de la actividad por una parte significativa de piscicultores. Sin embargo, a pesar de los problemas técnicos y de gestión identificados, la piscicultura ha mostrado importancia en la diversificación de los ingresos y la seguridad alimentaria de la familia de piscicultores asistidos.
\end{abstract}

Palabras clave: Agricultura Familiar. Producción de Pescado. Calidad del Agua 


\section{INTRODUÇÃO}

A aquicultura tem destaque mundial, por ser uma atividade que permite um rápido crescimento na produção de alimentos nutritivos e saudáveis. Contribui significativamente para a geração de emprego e renda, e por conseguinte, para a diminuição da pobreza e da fome em diversas partes do mundo (SIQUEIRA, 2018). O crescimento da população mundial, a preocupação com a segurança alimentar e o interesse cada vez mais intenso em relação à sustentabilidade ambiental estão entre os principais desafios a serem enfrentados pelos países para as próximas décadas (SCHULTER; VIEIRA FILHO, 2017). Em 2014, segundo a Organização das Nações Unidas para a Alimentação e Agricultura (FAO, 2016), a produção mundial de pescado atingiu a marca de 167 milhões de toneladas, com 73,8 milhões de toneladas provenientes da aquicultura.

A produção de pescado, que por muitos anos teve sua origem da pesca e que atualmente passa por uma estagnação, sobretudo pela exploração dos estoques pesqueiros, encontrou na aquicultura a saída para a continuidade do crescimento sustentável. No ano de 2019, foram registradas cerca de 758.006 toneladas de peixes de cultivo no Brasil (PEIXE BR, 2020).

Apesar dos números atuais animadores, a exploração racional e sustentável para o desenvolvimento da piscicultura ainda é muito deficitária, especialmente pela lentidão de difusão de tecnologias e ausência de informações sobre as particularidades de cada região produtora. Esse tipo de atividade, formada principalmente por produtores que a utilizam para subsistência ou por aqueles que comercializam apenas pequena parte de sua produção, é realizada de forma muito simples e, segundo a FAO (1994), a atividade é paralisada pela maioria quando cessa a ajuda do Estado.

O pescado é uma das fontes de proteína mais equilibradas em nutrientes, de fácil digestibilidade e de grande importância na nutrição humana (ANDRADE; BISPO; DRUZIAN, 2009). É inquestionável sua qualidade nutricional e sua importância no incremento do valor nutricional das dietas das populações mais carentes. Incentivar à agricultura familiar, fundamental para o desenvolvimento rural, tem grande potencial na contribuição para a segurança alimentar e nutricional, na geração de renda no campo e das economias locais, preservação dos alimentos tradicionais e da agrobiodiversidade (ELIAS et al., 2019).

A região do Baixo Parnaíba, segundo o Plano Territorial de Desenvolvimento Rural Sustentável (BRASIL, 2005), possui 16 municípios em sua maior parte inseridos na Mesorregião Leste Maranhense. O município de Araioses encontra-se na Microrregião Geográfica do Baixo Parnaíba e no censo demográfico registrou 42.505 habitantes, dos quais 12.045 habitantes na área 
urbana e 30.460 na área rural. Possui baixo índice de desenvolvimento humano (0,521), (IBGE, 2010) e as principais fontes de recursos para o município são a pecuária, extração vegetal, lavoura permanente ou temporária, trabalho informal e as transferências governamentais (FILHO, 2011).

Para que a piscicultura possa favorecer também as pessoas de baixa renda, é fundamental que os programas desenvolvidos especificamente para este fim sejam elaborados a partir de informações sobre a realidade socioeconômica. Assim, para sanar os entraves na disseminação de tecnologia, há necessidade imediata de promover a integração entre geradores de tecnologias (Universidades), com possíveis entidades difusoras (cooperativas, associações de produtores, sindicatos rurais, escolas etc.), a fim de desenvolver trabalhos e repassar informações já existentes que possam atender as necessidades deste nicho produtivo (BRASIL, 2010a).

Diversos estudos, sobretudo no Norte e Nordeste, têm buscado caracterizar a piscicultura para o desenvolvimento da atividade (ARAÚJO; SÁ, 2008; CARVALHO; SOUZA; CINTRA， 2013; ESTEVÃO-RODRIGUES; LIMA; ESTEVÃO-RODRIGUES， 2017 NAKAUTH; NAKAUTH; NÓVOA, 2015; OLIVEIRA; FLORENTINO, 2018). Conhecer as limitações da atividade e suas características locais possibilita o desenvolvimento de políticas para alavancar a produção, fornecendo subsídios de incentivo à agricultura familiar, fundamental ao desenvolvimento rural pela contribuição para geração de emprego e renda e por conseguinte, segurança alimentar (ELIAS et al., 2019). Na literatura são inexistentes informações da situação socioeconômica dos produtores bem como das características da piscicultura desenvolvida no município de Araioses.

Diante desse contexto, este trabalho objetivou caracterizar a piscicultura no município de Araioses/MA, como forma de reconhecer e melhorar a atividade, a fim de subsidiar o desenvolvimento socioeconômico da região.

\section{MATERIAIS E MÉTODOS}

O estudo foi realizado no período de janeiro/dezembro de 2018, no município de

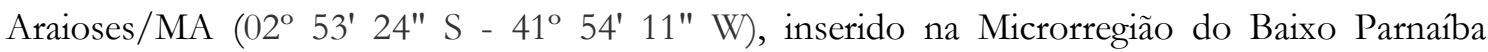
Maranhense. As atividades do estudo foram realizadas por um grupo interdisciplinar da Universidade Federal do Maranhão (UFMA), campus Chapadinha, com o apoio do Instituto Federal do Maranhão (IFMA), campus Araioses.

A pesquisa foi dividida em três fases. $\mathrm{Na}$ fase I ocorreu a sensibilização e explanação dos objetivos da pesquisa e o levantamento do perfil socioeconômico das famílias dos criadores. Os piscicultores foram indicados por líderes da comunidade, sendo selecionados somente aqueles 
que desempenhavam a piscicultura ativamente (independentemente do tamanho da criação). Os dados foram coletados por meio de questionário semiestruturado apresentando questões referentes à caracterização da infraestrutura, do sistema de criação, espécies criadas, comercialização, importância econômica da atividade em relação a renda da família, filiação à associações, dificuldades e sugestões para desenvolvimento da piscicultura. Os dados foram analisados por meio de estatística descritiva.

$\mathrm{Na}$ fase II, ocorreram 3 palestras de capacitação aos criadores, com o objetivo de orientar os princípios básicos da criação de peixes. Os temas de palestras foram sugeridos pelos próprios produtores, sendo abordado temas como importância da qualidade da água no cultivo, benefício da calagem (calcário agrícola) e manejo alimentar dos peixes (tipo de alimento, quantidade e frequência alimentar). Durante 8 meses, mensalmente, foram analisados os parâmetros de qualidade de água dos tanques de cada criador, assim como a alimentação administrada no período. Em relação à água de cultivo, foram avaliados o pH, o oxigênio dissolvido, a transparência e a salinidade. O oxigênio dissolvido e a temperatura foram medidos com oxímetro digital (Alfakit modelo AT170), o pH da água foi monitorado com um pHmetro (Alfakit AT315), a transparência da água determinada pelo disco de Sechi e a salinidade por um refratômetro manual (os equipamentos utilizados nas análises pertencem a UFMA).

$\mathrm{Na}$ fase III, ocorreu um encontro final (confraternização) entre a equipe da pesquisa e os criadores onde cada piscicultor recebeu um resumo dos dados da qualidade da água observados mensalmente durante todo o período e uma minicartilha sobre principais cuidados a serem observados durante a criação.

\section{RESULTADOS E ANÁLISES}

\section{Perfil socioeconômico}

Foram identificados 25 criadores de peixes no município, entretanto apenas 13 criadores foram acompanhados durante todo o desenvolvimento do estudo. Doze criadores foram excluídos, porque haviam desistido da criação recentemente e encontravam-se com os viveiros/tanques secos. A justificativa pela desistência foi, principalmente, relacionada à escassez de água durante a época da estiagem na região (meses de julho a dezembro) nos anos anteriores e por falta de recurso para manter a criação. Todos mantêm a criação de forma muito simples e com recursos próprios, sendo caracterizada como atividade de subsistência. De acordo com Nakauth, Nakauth e Nóvoa (2015), a precariedade da gestão no controle dos custos de produção é um dos fatores significativos do abandono da atividade. 
Dos 13 criadores assistidos, dez eram homens e apenas três eram mulheres. Quanto à faixa etária do criador, $50 \%$ deles têm entre 51 e 60 anos, estado civil casado $(69 \%)$ e todos possuem filhos. A grande maioria deles é natural do município de Araioses (94\%). O meio rural brasileiro tem se tornado cada vez mais idoso e masculino, havendo exceções na predominância feminina em atividades específicas (CAMARANO; ABRAMOVAY, 2014).

Quanto à localização da residência, 63\% dos criadores residem na zona rural em casa própria $(94 \%)$ e de alvenaria ou barro $(87 \%)$. Todos os criadores têm energia elétrica em suas casas e $81 \%$ possuem poço artesiano como fonte de água para consumo da família.

Oliveira e Florentino (2018) relataram resultados semelhantes caracterizando pisciculturas de Porto Grande-AP, constataram 100\% das casas próprias entre os criadores, predominância de poço artesiano como fonte de água e fornecimento de energia elétrica nas residências. Contudo, em relação ao tipo de moradia, se sobressaiu as moradias de madeira em relação às de alvenaria ou barro, mais comum entre os piscicultores do município de Araioses. As construções de barro/taipa são um costume na região do estudo, mas também de forma geral no interior do Maranhão. O material se adapta termo acusticamente, com excelência, ao clima quente e úmido (MARTINS, 2005).

Em relação à escolaridade, nenhum dos criadores acompanhados em Araioses tem curso superior. O maior percentual de escolaridade observado foi o ensino fundamental completo (44\%), seguido de ensino fundamental incompleto (38\%). Neste contexto, diversos estudos afirmam menores níveis de escolaridade na região Norte-Nordeste (OLIVEIRA; FLORENTINO, 2018; RIBEIRO-NETO et al., 2016; SILVA et al., 2013; ZACARDI et al., 2017). Esse aspecto enfatiza a dificuldade de implantação de novas tecnologias e conhecimentos de gestão da atividade, o que implica prejudicialmente o desenvolvimento da piscicultura na região.

Quanto ao tempo na atividade de criação, 63\% afirmaram criar há mais de três anos, tendo a participação da família $(63 \%)$ no desenvolvimento da atividade.

Em relação à participação em algum programa social do governo, a grande maioria dos criadores em Araioses afirmou que recebeu o auxílio do Programa Federal Bolsa Família (83\%) e o Seguro Defeso (17\%) na época da piracema dos peixes (os que recebem o seguro defeso também se apresentaram como pescadores). Em contrapartida, quanto aos programas diretamente voltados para o desenvolvimento de atividade rural, 94\% dos piscicultores nunca chegaram a dispor de crédito bancário para auxiliar na criação. Com frequência questionavam se o trabalho que estava sendo desenvolvido pelos pesquisadores (em Araioses) ocasionaria em crédito para a atividade. 
A ausência de crédito rural é um fator preocupante no município, visto que o município possui um baixo IDH $(0,521)$ e a população em sua maioria sobrevive de atividades relacionadas à agricultura familiar. Este fator dificulta o desenvolvimento e manutenção das atividades que podem gerar impacto positivo na economia regional, e assim os criadores/população se tornam dependentes de programas como o Bolsa Família.

Conforme observado in loco, os produtores executam a atividade utilizando muito pouco insumos básicos para criação e terminam por abandonar a atividade por perceberem que a atividade não é rentável, pois o manejo deficiente ocasionado pela falta de recursos mascara a boa produtividade que a atividade poderia alcançar.

Além da piscicultura, os produtores relataram desenvolver outras atividades na propriedade rural, principalmente a de agricultor, apresentando o piscicultor como um ator multifuncional, igualmente exposto por Baccarin et al. (2009) e Nakauth, Nakauth e Nóvoa (2015). A piscicultura surge como alternativa de diversificação da produção e de renda, além de viabilizar a obtenção de um produto que há alguns anos era facilmente encontrado em ambientes naturais através da pesca, mas que atualmente é escasso (CORRÊA; MOTA; MEYER, 2010).

Não foi possível mensurar entre os entrevistados a renda obtida com a piscicultura, devido à dificuldade deles em definir tanto o preço de venda, quanto o que é gerado de lucro por atividade, seja ela da criação de peixes ou das demais atividades agropecuárias desenvolvidas na propriedade. Esse fato se reflete no Brasil de uma forma geral, devido muitos piscicultores de fato não conhecerem o rendimento real gerado pelas atividades desenvolvidas ou por considerarem este assunto como particular e optam por não informar as questões referentes a essa temática (BRASIL, 2010b). A gestão é um fator que deve ser trabalhado entre o grupo dos piscicultores entrevistados em Araioses, pois poderá identificar os custos de produção reduzindo os custos desnecessários e/ou redefinir estratégias de comercialização do produto gerado.

\section{Características das unidades de cultivo}

A área dos viveiros de peixes no município varia em relação ao tipo de viveiro. Viveiros escavados e revestidos apresentam áreas entre $500 \mathrm{~m}^{2}$ e $2.700 \mathrm{~m}^{2}$ e os tanques-rede (gaiolas) de $6 \mathrm{~m}^{3}$ a $12 \mathrm{~m}^{3}$. A maioria cria em viveiros escavados no solo (10 produtores), dois produtores criam em tanques-rede e um deles em tanques revestidos por lona plástica. Os tanques-rede com profundidade de 1,5 m e os demais com média de 1,2 $\mathrm{m}$. Os viveiros escavados são os meios produtivos mais utilizados e difundidos nas pisciculturas do país para a produção de peixes (SCHULTER; VIEIRA FILHO, 2017). Segundo Trombeta, Trombeta e Mattos (2015), as principais vantagens desse sistema são: disponibilidade de alimentação natural nos viveiros 
(fitoplâncton) e, consequentemente, melhor conversão alimentar, possibilidade de correção da qualidade da água e maior segurança quanto a furtos. Além disso, pode ser facilmente implementado em pequenas propriedades rurais (familiares) ou em produção em larga escala (BARBOSA; PANTOJA-LIMA, 2016; BARROS; ESPAGNOLI; SOUZA, 2011; RIBEIRONETO et al., 2016)

Em Araioses, os criadores que produzem em viveiros escavados sofrem influência das marés e apresentam uma grande variação da salinidade. Entretanto, os que criam em tanques-rede mantêm os mesmos numa lagoa natural perene que recebe água diretamente do Rio Magu e não sofrem efeito das marés e salinidade.

Os tanques redes utilizados foram projetados e construídos pelos próprios produtores, com estruturas metálicas, tela plástica resistente e bombonas de plástico para flutuação. O baixo número de produtores (dois) que adotaram este sistema pode estar relacionado ao maior recurso hídrico nas propriedades. Apesar do custo relativamente alto para a aquisição deste sistema de cultivo, estes produtores afirmam que vale a pena o investimento. Normalmente, este tipo de cultivo privilegia a produção em sistema intensivo, devido à produção em altas densidades. Podese exaltar a facilidade de manejo, o arraçoamento e principalmente a despesca de forma fracionada, em detrimento da dificuldade dos tanques escavados (SCHULTER; VIEIRA FILHO, 2017).

Quanto às estruturas de abastecimento e drenagem da água (nos viveiros escavados), todos produtores utilizam bomba elétrica para esvaziar os viveiros. Não foi observada nenhuma estrutura de drenagem comumente utilizada na criação de peixes (monge ou modelo cotovelo). Observou-se que a água residual da criação é descartada de um viveiro a outro ou diretamente no Rio. Esta prática não é recomendada, pois cada viveiro deve ter sua saída de água individual sem reutilização, para que se consiga manter o sistema livre de doenças. Neste caso, o controle sanitário fica prejudicado e a perda dos animais em caso de enfermidades será maior, além do impacto ambiental pelo descarte inadequado desse efluente, com risco de contaminação do meio aquático (MACEDO; SIPAÚBA-TAVARES, 2010). Como sugestão foi recomendado a utilização da água residual na irrigação de hortas domésticas como fonte de nutrientes para as plantas, por se apresentar como uma alternativa viável para a produção de alimentos com perda mínima de água e aproveitamento de nutrientes (MORAES et al, 2014).

\section{Espécies cultivadas e procedência dos alevinos}


Dentre as espécies criadas, a tambatinga (híbrido do cruzamento da fêmea do tambaqui (Colossoma macropomum) x macho da pirapitinga (Piaractus brachypomus) é a espécie nativa de maior interesse na região (44\%), seguidas pela tilápia (Oreochromis niloticus) (35\%), que é uma espécie exótica, e o camurupim (Megalops atlanticus), espécie marinha e exótica, também conhecido no Maranhão como pema (17\%). Os alevinos de tambatinga e tilápias utilizados pelos piscicultores são comercializados de municípios do Maranhão (Tutóia, Santa Rita e São Bento), Piauí (Parnaíba; Buriti dos Lopes; Piripiri) ou Ceará (Figura 1). Os exemplares de pema são coletados pelos próprios piscicultores em ambiente natural (lagoas temporárias). Costumam efetuar a compra dos alevinos individualmente $(69 \%)$, arcando assim com todos os custos de transporte ou frete. Neste caso, a adoção de sistema de parceria entre os piscicultores facilitaria a diminuição de custos de produção e possivelmente geraria mais renda, visto que o frete e ou custos com o combustível para transporte seriam compartilhados.

Figura 1 - Procedência dos alevinos durante o cultivo de peixes no município de Araioses/MA

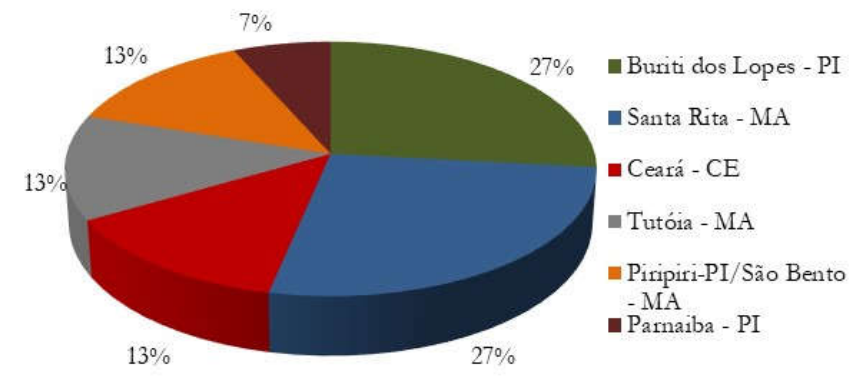

Fonte: Dados obtidos através de pesquisa em campo, 2018.

Zacardi et al. (2017) também relataram os híbridos tambacu e tambatinga como as espécies mais criadas em Santarém-PA, assim como Barros, Espagnoli e Souza (2011), na Baixada Cuiabana. Quanto à tilápia, apesar de ser uma espécie exótica, ainda é a mais cultivada nas diversas regiões do país (BACCARIN et al., 2009; CARVALHO; SOUZA; CINTRA, 2013; RIBEIRO-NETO et al., 2016).

Em Araioses, as tilápias criadas não são revertidas sexualmente e, por isso, muitos criadores reclamam da excessiva reprodução da espécie, o que ocasiona baixo crescimento. Estevão et al. (2017) destacam o risco ambiental da inserção de uma espécie exótica em ecossistemas naturais e os impactos negativos ocasionados, sobretudo pelo crescimento e reprodução acelerada em um habitat sem predadores naturais. 
O interesse dos piscicultores de Araioses pela tilápia é devido à alta resistência em relação à qualidade da água (LIMA; BERGAMIM; MORO, 2013), principalmente pela alta salinidade durante a época de estiagem (agosto a novembro). Com a redução do nível dos rios e o adentramento da água da maré em alguns viveiros, a alta salinidade é considerada um dos entraves da atividade na região, pois impede desenvolvimento dos peixes e maior aproveitamento produtivo dos insumos empregados na criação, além de impossibilitar aos produtores criar uma maior diversidades de espécies que podem se mostrar atrativas ao consumidor local. Em relação ao camurupim, o interesse é porque apresenta boa resistência tanto em água doce ou salobra (SEYMOUR.; WEGNER; GRAHAM, 2008), além do valor comercial na região.

Em relação ao interesse pela tambatinga, os criadores afirmam apreciar o sabor da carne, ela ter resistência à qualidade da água e maior crescimento em relação ao tambaqui.

\section{Manejo com os peixes}

Considerando o manejo utilizado com os animais, principalmente em relação à alimentação e à qualidade da água, o sistema de criação em Araioses foi considerado como extensivo, baseado em que quase nunca ocorre troca de água e na maioria das vezes esta troca só ocorre no período das chuvas.

De acordo com Scorvo Filho (2007), o sistema extensivo, muito utilizado por pequenos produtores em pequenas áreas de espelho de água, não se utiliza ração comercial, mas os subprodutos agrícolas, resultando em baixo custo e baixa produtividade. Os autores afirmam que, no Brasil, o principal sistema de criação na piscicultura é o semi-intensivo, sendo caracterizado por aplicar alguma tecnologia de criação, como: viveiros-berçários, ração comercial e certo nível de controle da qualidade da água.

Quanto às densidades de estocagem durante o cultivo, os produtores mantêm as taxas acima das recomendadas, tecnicamente. De acordo com Lima, Bergamim e Moro (2013), a engorda de tilápia criada de forma extensiva deve ser feita observando a taxa de estocagem de 500 a 1000 alevinos/ha. Segundo o relato, os produtores utilizam taxas de estocagem de 3 a 5 vezes maior do que o recomendado. Contudo, relataram a prática de múltiplas despescas durante o mesmo ciclo de produção, o que diminui a densidade de estocagem durante o cultivo. É comum entre os produtores que produzem em pequena escala não terem controle sobre as taxas de estocagem adequadas (BARBOSA; NAKAUTH; NAKAUTH; NÓVOA, 2015; PANTOJALIMA, 2016). Em relação à criação de tilápias em tanques-rede, a densidade utilizada em Araioses é de em média 1.500 alevinos $/ \mathrm{m}^{3}$ e a recomendação é de no máximo 400 peixes $/ \mathrm{m}^{3}$, segundo Lima, Bergamim e Moro (2013). Izel e Melo (2004) definiram um protocolo de sistema de 
produção para tambaqui e tambatinga em sistema semi-intensivo em que recomendam 10 alevinos $/ \mathrm{m}^{2}$.

Quanto ao fornecimento de ração, os criadores utilizam ração comercial (87\%), tipo extrusada, administrada duas vezes ao dia (56\%), (Figura 2). Os produtores foram orientados que nos meses iniciais de criação a alimentação deve ser administrada de 3 a 6 vezes ao dia e, na recria/engorda, 2 a 3 vezes (LIMA; BERGAMIM; MORO, 2013).

Figura 2 - Frequência do uso de ração comercial durante o cultivo de peixes no município de Araioses/MA

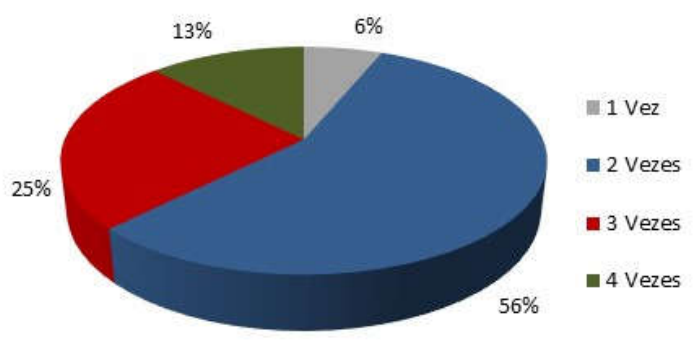

Fonte: Dados obtidos através de pesquisa em campo, 2018.

Alguns relataram que, quando os recursos ficam escassos, alimentam os peixes somente uma vez ao dia ou deixam de alimentar por até uma semana. Os piscicultores, em sua maioria, recorrem à alimentação complementar no terço final da criação como o intuito de redução dos custos produtivos. Esta alimentação é baseada, principalmente, em mandioca e milho (89\%), culturas que a maioria dos produtores cultiva também para subsistência. O uso desta prática na alimentação dos peixes é observado com frequência na piscicultura familiar (ARAUJO; SÁ, 2008; CARVALHO; RIBEIRO-NETO et al., 2016; CARVALHO; SOUSA; CINTRA, 2013).

Melo et al. (2010), na região de Dourados-MS, destacaram que os gastos com ração somado à mão de obra representam quase 50 \% dos custos de produção. Meante e Dória (2017) relataram o preço desse insumo como principal fator limitante ao desenvolvimento da piscicultura no estado de Rondônia. Desta forma, pode ser observado que a utilização de alimentação alternativa de forma geral é uma estratégia que os piscicultores familiares utilizam para reduzir os custos de produção e se manterem na atividade.

A partir das observações em relação ao manejo alimentar (frequência, quantidades em relação à biomassa e tipo de alimento) adotados pelos criadores, foi realizada uma palestra (Fase II) apresentando a importância do controle da quantidade de alimento administrado por 
fases/peso, frequência de alimentação e alimentos alternativos (no caso da falta da ração comercial ou para complementação). Entretanto, apesar do reconhecimento da importância deste controle, esta prática nem sempre foi utilizada pelos criadores. Foram justificadas a falta de recursos financeiros para administrar uma maior quantidade de ração/dia, a falta de controle do número de peixes/área (biomassa) ou disponibilidade de tempo para alimentações com maior frequência.

Quanto à utilização de água para o cultivo (Figura 3), a grande maioria utiliza água direto do Rio Magu ou Rio Santa Rosa (afluentes do Rio Parnaíba) e nenhum dos criadores tem controle sobre a qualidade da água durante o cultivo. O custo e a dificuldade do acesso aos equipamentos, aliado à falta de informação de como utilizá-los, foram fatores limitantes verificados entre os piscicultores de Araioses para a adoção da prática. Estes resultados são similares ao exposto por Zacardi et al. (2017), onde 67\% dos criadores avaliados em seu estudo não realizam controle da qualidade da água, e 100\% não realiza tratamento de efluente.

A qualidade da água na aquicultura está relacionada a diversos fatores, como a origem da água, o manejo empregado e as espécies utilizadas, tornando fundamental o emprego de boas práticas de manejo que visem proporcionar o meio ideal da produção, minimizar os impactos ambientais pela mesma (MACEDO; SIPAÚBA-TAVARES, 2010).

O controle da qualidade da água está entre as Boas Práticas de Manejos (DOTTA; PIAZZA, 2012), contudo na piscicultura familiar essa prática ainda não está difundida.

Figura 3 - Principais fontes da água utilizada na criação de peixes no município de Araioses/MA

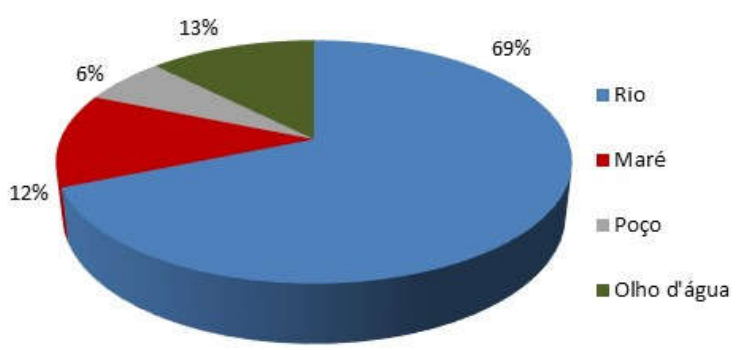

Fonte: Dados obtidos através de pesquisa em campo, 2018.

Os produtores, apesar de não executarem medidas de controle de qualidade de água, se mostraram bastante atentos e preocupados com esta questão, pois relataram perceber um menor consumo de alimento e "perturbação" dos peixes nos meses de seca. Diante disso, os parâmetros de qualidade de água em todos os viveiros foram monitorados e avaliados mensalmente (a temperatura, oxigênio dissolvido, $\mathrm{pH}$, transparência e salinidade da água). Além disso, como parte 
da Fase II da pesquisa, foi realizada uma palestra para esclarecer a importância do manejo da qualidade da água durante o cultivo.

Os valores médios observados destes parâmetros, de uma forma geral, não variam muito no decorrer dos meses de acompanhamento. O parâmetro que variou foi a salinidade na época da estiagem (Tabela 1).

Tabela 1- Parâmetros de qualidade avaliados nas pisciculturas de Araioses durante o desenvolvimento da pesquisa

\begin{tabular}{|c|c|c|c|c|c|}
\hline \multirow[b]{2}{*}{ Meses } & \multirow[b]{2}{*}{$\begin{array}{c}\text { Temperatura } \\
\left({ }^{\circ} \mathrm{C}\right)\end{array}$} & \multirow[t]{2}{*}{$\mathbf{P h}$} & \multirow{2}{*}{$\begin{array}{c}\mathrm{OD}^{1} \\
(\mathrm{mg} / \mathrm{L})\end{array}$} & \multirow[b]{2}{*}{$\begin{array}{c}\text { Salinidade } \\
(\%)\end{array}$} & \multirow{2}{*}{$\begin{array}{c}\text { Transparência } \\
\text { (cm) }\end{array}$} \\
\hline & & & & & \\
\hline Abril & 30,1 & 7,2 & 7,1 & 0 & 40 \\
\hline Maio & 29,4 & 7,0 & 5,5 & 0 & 40 \\
\hline Junho & 30,8 & 7,0 & 7,1 & 0 & 40 \\
\hline Julho & 30,2 & 7,7 & 6,2 & 0 & 40 \\
\hline Agosto & 29,6 & 7,8 & 5,9 & 4,0 & 30 \\
\hline Setembro & 29,2 & 7,8 & 6,5 & 5,0 & 30 \\
\hline Outubro & 31,7 & 8,0 & 7,1 & 5,5 & 30 \\
\hline Novembro & 31,0 & 7,5 & 6,0 & 6,0 & 30 \\
\hline
\end{tabular}

1-OD: oxigênio dissolvido

Fonte: Dados médios de todos os viveiros avaliados através de pesquisa em campo, 2018.

A temperatura da água apresentou valor médio de $30^{\circ} \mathrm{C}$. Para as espécies amazônicas, como o tambaqui e tambatinga, temperaturas mais próximas de $28^{\circ} \mathrm{C}$ são as mais adequadas para o crescimento dos peixes (BALDISSEROTTO, 2013). Quanto maior a temperatura, maior o consumo de oxigênio e menor a disponibilidade deste gás no ambiente. Os níveis de oxigênio se mantiveram na faixa de 5,5 a 7,1 mg/L, se apresentando dentro do nível desejável (acima de 5,5 $\mathrm{mg} / \mathrm{L})$.

Em duas propriedades foram encontrados (2 viveiros) um grande número de macrófitas aquáticas. Considerando não ser favorável aos peixes a presença destas plantas, porque prejudicam o manejo de rotina e no período noturno consomem o oxigênio dissolvido na água, foi recomendado a criadores a retirada desta vegetação. Eles aceitaram a sugestão e fizeram a retirada das plantas dos viveiros.

Quanto ao pH da água, a variação $(7,0$ a 8,0$)$ deste parâmetro se manteve na faixa ideal aos peixes, que é de 6,5 a 8,5 (MACEDO et al., 2010). Em duas propriedades, em um tanque de cada criador, foi identificado baixo nível de $\mathrm{pH}(\mathrm{pH} 3$,5). Nestes tanques, os produtores relataram mortalidade de alguns peixes ou baixo consumo de alimento. Foi recomendado o uso de calcário agrícola para correção do $\mathrm{pH}$ da água (observando o $\mathrm{pH}$ e a área de cada viveiros). Após dois meses de uso do calcário, o $\mathrm{pH}$ da água nestes tanques se menteve proximo de 6,5 , cessando a 
mortalidade. Nenhum dos criadores usavam a prática de calagem para corrigir o $\mathrm{pH}$, por falta de conhecimento ou por não ter recurso para aquisição. Neste sentido, foi realizada uma palestra sobre uso de calcáreo agrícola como parte da Fase II da pesquisa.

A salinidade é o parâmetro que mais prejudica a criação nos meses de estiagem na região, ou seja, entre o período de agosto a novembro. Nestes meses, por causa da ausência de chuva, os níveis de salinidade variam de 4,0 - 6,0 \% em alguns locais. Os produtores que sofrem mais com a alta salinidade da água relatam que os peixes comem menos e consequentemente não crescem neste periodo. Neste sentido, a recomendação a estes produtores foi de tentar manter a criação semente no período de maior disponibilidade de água (nas chuvas). A transparência da água em todas as criações se manteve dentro da faixa recomendada que é de 30 a $60 \mathrm{~cm}$ (LEIRA et al., 2017).

A regularidade de acompanhamento desses parâmetros é fundamental, uma vez que eles estão interligados e são responsáveis pelas principais atividades fisiológicas dos peixes, como a respiração, alimentação e reprodução (LEIRA et al., 2017). Medeiros Júnior, Cordeiro e Silva (2018), ao avaliar os parâmetros físico-químicos da água em viveiros de piscicultura, também não observaram oscilação de forma geral, mantendo-se dentro da faixa recomendada para criação de peixes.

Os piscicultores desenvolvem a produção sem nenhum acompanhamento técnico do governo, seja estadual ou municipal. A deficiência de assistência técnica é um dos principais entraves na aquicultura (CARVALHO; SOUSA; CINTRA, 2013), levando ao descrédito da atividade ou até mesmo ao abandono, uma vez que sua ausência acomete em erros e perdas na produção (ARAÚJO; SÁ, 2008). No município de Araioses observou-se essa limitação como uma das principais dificuldades para o desenvolvimento da piscicultura regional.

Em relação à despesca para venda, grande parte dos criadores (69\%) utiliza como critério o peso dos animais e não o tempo de cultivo. Quando os peixes atingem o peso desejado, definido pelos piscicultores, em torno de 250 a 400 gramas (ou três peixes pesando $\pm 1,0 \mathrm{~kg}$ ), comercializam o pescado in natura na própria comunidade. A produção em pequena escala não permite periodicidade na oferta do produto, logo, não desperta interesse de compradores externos (intermediários, feirantes, outros). Além disso, os custos (combustível, gelo) ou condição de transporte para buscar esse pescado nas propriedades diminuiria significativamente o preço de venda, tornando a comercialização do mesmo inviável. O preço comercializado pelo kg diretamente aos vizinhos custa em torno de $\mathrm{R} \$ 10,00$ para as principais espécies.

Não foi possível acompanhar durante o período nenhuma atividade de despesca total, porque as visitas eram mensais e as despescas ocorriam de forma parcelada em função do peso 
dos animais. A secagem total dos viveiros quase nunca ocorre, pois, quando secam, não conseguem fazer a drenagem completa. A falta desta prática tem contribuindo para a ocorrência de predadores no local, ocasionado problemas na introdução de um novo lote (DOTTA; PIAZZA, 2012). Diante desta situação foram repassadas orientações sobre como proceder durante a secagem dos viveiros escavados. Priorizar a exposição ao sol por 10 dias, seguida do uso cal virgem (Óxido de cálcio- $\mathrm{CaO}$ ) com o objetivo de desinfecção e morte de espécies indesejadas (IWASHITA; MACIEL, 2013).

Durante as visitas mensais, tentou-se o acompanhamento de algumas pesagens com intuito de observar o desenvolvimento do pescado, e corrigir a quantidade de ração administrada. Contudo, devida a várias despescas feitas pelos piscicultores entre um período e outro, e como alguns não têm controle da biomassa, estes dados não puderam ser contabilizados e, portanto, não são apresentados neste estudo.

Elias et al. (2019) destacam a importância de políticas públicas voltadas à agricultura familiar para o desenvolvimento rural, sobretudo de comercialização, como via de inserção de produtores familiares no mercado. Seguindo este ponto de vista, a introdução de cooperativas que trabalhassem não somente a comercialização, mas também a gestão de custos na atividade, seria um ponto a ser trabalhado no município, na medida que estes vendem seu produto sem nenhuma agregação de valor e têm dificuldade de definir preços de comercialização condizente com os seus gastos.

\section{Ações de capacitação e impactos na piscicultura local}

A partir das ações de capacitações com as palestras e orientações in loco durante as visitas mensais (Fase II), acreditamos ter contribuído em relação ao manejo que os criadores vinham realizando, principalmente por desconhecerem algumas técnicas básicas, mas também por se sentirem mais "assistidos" em relação à criação. Com certeza, apesar das inúmeras limitações observadas entre os piscicultores, eles tentaram corrigir dentro do possível os erros praticados com o objetivo de ter uma maior produção, na diversificação da renda e complemento na segurança alimentar das famílias.

No encerramento da pesquisa (Fase III), foi realizada uma confraternização onde foi entregue para cada criador uma tabela com os dados da qualidade da água dos viveiros/tanques no período do projeto e uma minicartilha ilustrativa com algumas recomendações e cuidados para serem observados durante o cultivo. 


\section{CONSIDERAÇÕES FINAIS}

O perfil do piscicultor entrevistado na região de Araioses/MA foi caracterizado como piscicultor de base familiar, visto que têm como principal força de trabalho a mão de obra familiar e utilizam o produto gerado pela piscicultura para complementação de renda. Eles não realizam controle da qualidade de água dos viveiros, seja pela falta de informação ou por não possuir os equipamentos para realizá-la. A grande maioria dos piscicultores trabalha de forma individual e informal, possuindo limitações em relação à gestão, planejamento e principalmente manejo geral da atividade, além da deficiência de recursos e de infraestrutura. Outras questões importantes observadas foram a carência de investimento do governo e a falta de assistência técnica durante o cultivo.

Durante as ações de extensão realizadas durante o estudo, conseguiu despertar para a importância do manejo correto durante a criação de peixes. Considerando as particularidades, as experiencias e as carências individuais de cada produtor, a maioria mostrou interesse durante as visitas, e também se mostraram abertos a novos conhecimentos.

O objetivo principal deste estudo foi o de caracterizar a piscicultura visando estratégias para desenvolver a atividade na região. Embora a caracterização da piscicultura tenha sido alcançada, os resultados também mostraram alguns gargalos a serem resolvidos, principalmente em relação à carência de investimento do governo e à falta de assistência técnica.

Foi observada a dependência direta ou indireta da agricultura/piscicultura para a sua subsistência, sendo inquestionável a contribuição da piscicultura como ferramenta para a segurança alimentar e nutricional das famílias envolvidas.

Apoio: Este estudo recebeu recurso financeiro da Fundação de Amparo à Pesquisa e ao Desenvolvimento Científico e Tecnológico do Maranhão - FAPEMA.

\section{REFERÊNCIAS}

ANDRADE, G. Q.; BISPO, E. S.; DRUZIAN, J. I. Avaliação da qualidade nutricional em espécies de pescado mais produzidas no Estado da Bahia. Ciênc. Tecnol. Aliment., Campinas, v. 29, n 4, p. 721-726, 2009. Disponível em: http://www.scielo.br/pdf/cta/v29n4/04.pdf. Acesso em 16 de jun. de 2019.

ARAÚJO, J. S.; SÁ, M. F. P. Sustentabilidade da piscicultura no baixo São Francisco alagoano: condicionantes socioeconômicos. Revista Ambiente \& Sociedade, Campinas, v.11, n. 2, p. 405-424, 2008. Disponível em: http://www.scielo.br/scielo.php?script=sci_arttext\&pid=S1414753X2008000200013. Acesso em 18 de maio de 2019. 
BACCARIN, A. E. et al. Piscicultura em comunidade remanescente de quilombo: um estudo de caso. Revista Informações Econômicas, São Paulo, v. 39, n. 11, p. 42-47, 2009. Disponível em: http://www.iea.sp.gov.br/ftpiea/publicacoes/ie/2009/tec4-1109.pdf. Acesso em 16 de maio de 2019.

BALDISSEROTTO, B. Fisiologia de peixes aplicada a piscicultura. 3. ed. Santa Maria: Editora da UFSM, 2013. 352 p.

BARBOSA, H. T. B.; PANTOJA-LIMA, J. Características da piscicultura em Presidente Figueiredo, Amazonas. Revista Igapó-Revista de Educação Ciência e Tecnologia do IFAM, $\begin{array}{lllllll}\text { Amazonas, } & \text { v. } & 10, & \text { n. } & 1, & \text { p. } & 103-113,\end{array}$ http://200.129.168.183/ojs/index.php/igapo/article/view/440/367. Acesso em 12 de jul. de 2019.

BARROS, A. F. de; ESPAGNOLI, M. I. G. M.; SOUZA, O. M. de. Caracterização da piscicultura na microrregião da baixada cuiabana, Mato Grosso, Brasil. Boletim do Instituto de Pesca, São Paulo, v. 37, n. 3, p. 261-273, 2011.

BRASIL. Ministério do Desenvolvimento Agrário. Plano territorial de desenvolvimento rural sustentável. São Luís, maio, 2005. Disponível em: http://sit.mda.gov.br/download/ptdrs/ptdrs_territorio020.pdf. Acesso em 25 de set. de 2018.

BRASIL Secretaria Especial da Aquicultura e Pesca. Casos de Sucessos da Aquicultura no Brasil. Publicação de circulação nacional. Brasília- DF. 96 p., 2010a.

BRASIL Ministério da Pesca e Aquicultura. Boletim estatístico da pesca e aquicultura. 60 p. 2010b.

CAMARANO, A. A.; ABRAMOVAY, R. Exxodo rural, envelhecimento e masculinização no Brasil: panorama dos últimos cinquenta anos. Revista Brasileira de Estudos de População, Rio de Janeiro, v. 15, n. 2, p. 45-65, 2014.

CARVALHO, H. R. L. de; SOUZA, R. A. L.; CINTRA, I. H. A aquicultura na microrregião do Guamá, Estado do Pará, Amazônia Oriental, Brasil. Revista de Ciências Agrárias Amazonian Journal of Agricultural and Environmental Sciences, Amazonas, v. 56, n. 1, p. 1-6, 2013.

CORREAA, R.; MOTA, D.; MEYER, G. Tipologia da piscicultura familiar no nordeste paraense. Revista Agrotrópica, Bahia, v. 22, n.2, p. 75-88, 2010.

DOTTA, G.; PIAZZA, R.S. Manejo e Sanidade no cultivo. Curitiba. Instituto Federal do Paraná. 2012. 316p.

ELIAS, L.P. et al. Impactos socioeconômicos do Programa Nacional de Alimentação Escolar na agricultura familiar de Santa Catarina. Revista de Economia e Sociologia Rural, Brasília, v. 57, n. 2, p. 215-233, 2019.

ESTEVÃO-RODRIGUES, T. T.; LIMA, J. P.; ESTEVÃO-RODRIGUES, T. D. Piscicultura familiar, assistência técnica e práticas de manejo colheita e pós colheita: estudo de caso da região metropolitana de Manaus - Amazonas, Brasil. Revista Observatorio de la Economía 
Latinoamericana, $\quad 2017 . \quad$ Brasil, Disponível em: http://www.eumed.net/cursecon/ecolat/br/17/piscicultura.html. Acesso em 22 de abr de 2019.

FAO. Entre la acuicultura de los 'mas pobres' y la de los 'menos pobres'. Documento de Campo, n. 18. México: FAO, 1994.

FAO. The state of world fisheries and aquaculture: opportunities and challenges. Rome: FAO, 2016. 243 p.

FILHO, F. L. C. et al. Relatório diagnóstico do município de Araioses.31p. 2011.

IBGE. $\quad$ Araioses. $2010 . \quad$ Disponível em: https://cidades.ibge.gov.br/brasil/ma/araioses/panorama. Acesso em 02 de jul. de 2019.

IZEL, A. C. U.; MELO, L. A. S Criação de tambaqui (Colossoma macropomum) em tanques escavados no Estado do Amazonas. Manaus: Embrapa Amazônia Ocidental, 2004. 19p. Documentos, 32.

IWASHITA, M. K. P.; MACIEL, P.O. Princípios básicos de sanidade de peixes. In: Piscicultura de água doce: Multiplicando conhecimentos/ Editores Técnicos, Ana Paula O. Rodrigues... [et al.] Brasília. DF Embrapa, 2013, 440p.

LEIRA, M. H. et al. Qualidade da água e seu uso em pisciculturas. PUBVET, Londrina, v.11, n.1, p.11-17, jan. 2017. Disponível em: pubvet.com.br/artigo/3588/qualidade-da-aacutegua-eseu-uso-em-pisciculturas. Acesso em 18 de out. de 2019.

LIMA, A. F.; BERGAMIM, G. T.; MORO, G.V. Engorda de peixes. In: Piscicultura de água doce: Multiplicando conhecimentos/ Editores Técnicos, Ana Paula O. Rodrigues... [et al,] Brasília. DF Embrapa, 2013, 440p.

MACEDO, C. F.; SIPAÚBA-TAVARES, L. H. Eutrofização e qualidade da água na piscicultura: consequências e recomendações. Boletim do Instituto de Pesca, São Paulo, v. 36, n. 2, p. 149$163,2010$.

MARTINS, A. I. S. A taipa de pilão como método construtivo de casas populares. II Jornada Internacional de Políticas Públicas. São Luís - MA, 23 a 26 de agosto 2005.

MEANTE, R. E. X; DÓRIA, C. R. da C. Caracterização da cadeia produtiva da piscicultura no estado de Rondônia: desenvolvimento e fatores limitantes. Revista de Administração e Negócios da Amazônia, Porto velho, v. 9, n. 4, p. 164-181, 2017. Disponível em: http://www.periodicos.unir.br/index.php/rara/article/view/2617/2214. Acesso em 17 de set. de 2019.

MEDEIROS JÚNIOR, E. F. de; CORDEIRO, G. L.; SILVA, M. J. L. da. Qualidade da água em viveiros de tambaqui (Colossoma macropomum) (CUVIER, 1818), em São Gabriel da Cachoeira, Amazonas, Brasil. Revista Igapó - Revista de Educação Ciência e Tecnologia do IFAM, Amazonas, v. 12, n. 1, p. 22-31, 2018. Disponível em: http://200.129.168.183/ojs/index.php/igapo/article/viewFile/597/481. Aceso em 10 de jun. de 2019. 
MELO, A. X. de et al. A estratégia de dominação pelos custos na piscicultura sul-mato-grossense: o caso da região de Dourados/MS. Revista Brasileira de Gestão e Desenvolvimento Regional, Taubaté, v. 6, n. 1, 2010. Disponível em: https://www.rbgdr.net/revista/index.php/rbgdr/article/view/259. Acesso em 12 de jun. de 2019.

MORAIS, C. A. et al. Produção de alface (Lactuca sativa) em sistema compacto de aquaponia contendo juvenis 35 de tambaqui (Colossoma macropomum). 2014. In: Anais do Congresso Aquaciência / Foz do Iguaçu, Paraná.

NAKAUTH, A. C. S. S.; NAKAUTH, R. F.; NÓVOA, N. A. C. B. Caracterização da piscicultura no município de Tabatinga-AM. Revista Igapó-Revista de Educação Ciência e Tecnologia do IFAM, Amazonas, v. 9, n. 2, p. 54-64, 2015. Disponível em : http://200.129.168.183/ojs/index.php/igapo/article/view/311/289. Acesso em 18 de nov. de 2019.

OLIVEIRA, N. I da S. de; FLORENTINO, A. C. Avaliação socioeconômica dos piscicultores do município de Porto Grande, Amapá, Brasil. Ciência e Natura, Santa Maria, v. 40, p. 31, 2018.

PEIXE BR. Anuário brasileiro da piscicultura. Associação brasileira de piscicultura. Pinheiros-SP, 136p. 2019. Disponível em: https://www.peixebr.com.br/anuario-2020/. Acesso em 24 de julho de 2020.

RIBEIRO-NETO, T. F. et al. Piscicultura familiar extensiva no baixo São Francisco, estado de Sergipe, Brasil. Acta of Fisheries and Aquatic Resources, Sergipe, v. 4, n. 1, p. 62-69, 2016. Disponível em: https://seer.ufs.br/index.php/ActaFish/article/view/3020/4409. Acesso em 15 de maio de 2019.

SCORVO FILHO, J.D. Panorama da Aqüicultura Nacional - Instituo de Pesca de São Paulo. 2007. Disponível em: http://www.pesca.sp.gov.br/. Acesso em 08 de julho de 2020.

SEYMOUR, R. S.; WEGNER, N.C.; GRAHAM, J. B. 2008. Body size and the air-breathing organ of the atlanticus tarpon Megalops atlanticus. Comparative biochemistry and Physiology. Part A: Molecular \& Integrative Physiology, 150. 282- 287.

SILVA, A. P. da et al. Diagnóstico participativo da piscicultura familiar na região de Divinópolis/TO: Uma abordagem diferenciada para ações de pesquisa e desenvolvimento. Embrapa Pesca e Aquicultura. Boletim de Pesquisa e Desenvolvimento (INFOTECA-E), $92 \quad$ p., 2013.2 Disponível em: https://www.infoteca.cnptia.embrapa.br/bitstream/doc/982655/1/bpd2.pdf. Acesso em 19 de outubro de 2019.

SIQUEIRA, T. V. de. Aquicultura: a nova fronteira para produção de alimentos de forma sustentável. Banco Nacional de Desenvolvimento Econômico e Social (BNDES), Rio de Janeiro, v. 25, n. 49, p. 119-170, jun. 2018. Disponível em: https://web.bndes.gov.br/bib/jspui/bitstream/1408/16085/1/PRArt_Aquicultura\%20a\%20no va $\% 20$ fronteira_compl.pdf. Acesso em 22 de julho de 2020.

SCHULTER, E.P.; VIEIRA FILHO, J.E.R. Evolução da piscicultura no brasil: Diagnóstico e desenvolvimento da cadeia produtiva de tilápia. Texto para discussão / Instituto de Pesquisa 
Econômica Aplicada. Brasília: Rio de Janeiro: Ipea, 1990- ISSN 1415-4765. 2017. Disponível em: http://repositorio.ipea.gov.br/bitstream/11058/8043/1/td_2328.pdf. Acesso em: 27 de julho de 2020.

TROMBETA, T. D.; TROMBETA, R. D.; MATTOS, B. O. Criação de tilápias em viveiros escavados: guia técnico para empreender na criação de tilápias em viveiros. Brasília: Projeto Aqui Nordeste/SEBRAE. 2015. 96 p

ZACARDI, D. M. et al. Caracterização socioeconômica e produtiva da aquicultura desenvolvida em Santarém, Pará. Acta of Fisheries and Aquatic Resources, Sergipe, v. 5, n. 3, p. 102-112, 2017. Disponível em : https://seer.ufs.br/index.php/ActaFish/article/view/6491/6407. Acesso em 15 de maio de 2019

Recebido em: 08/03/2020

Aceito em: 06/08/2020 